\title{
SEASONAL CONCENTRATIONS OF ELEMENTS IN BOTH INDOOR AND OUTDOOR HOUSING IN PM $\mathrm{PM}_{2.5}$
}

\author{
AMGALAN NATSAGDORJ ${ }^{1}$, BULGANKHANGAI TUGSBAYAN ${ }^{1}$, TSELMUUNGARAV BATTUMUR $^{1}$, \\ BOLORMAA OYUNTSETSEG ${ }^{1}$, JIYI LEE ${ }^{2}$, YONG PYO KIM ${ }^{3} \&$ BATTSETSEG USUHBAYAR ${ }^{4}$ \\ ${ }^{1}$ Department of Chemistry, School of Arts and Sciences, National University of Mongolia, Mongolia \\ ${ }^{2}$ Department of Environmental Science and Engineering, Ewha Womans University, Republic of Korea \\ ${ }^{3}$ Department of Chemical Engineering and Materials Science, \\ Graduate Program in System Health Science and Engineering, Ewha Womans University, Republic of Korea \\ ${ }^{4}$ Department of Chemistry, School of Biomedicine, \\ Mongolian National University of Medical Sciences, Mongolia
}

\begin{abstract}
Young children and elders, who spend most of their time at home, are at high risk of indoor air pollution. Therefore, it is important to take appropriate measures to reduce the levels of air pollutants, in particular, PM. This study determined the elemental characteristics of indoor $\mathrm{PM}_{2.5}$ concentrations in ger, house, and apartments where fuel types were different. The indoor air samples of $\mathrm{PM}_{2.5}$ and elemental chemical species in each ger were collected and measured from December 2019 to August 2020 in 18 ger houses and apartments in the residential area (Songino-Khairkhan district) and city center area (Bayanzurkh district) of Ulaanbaatar. In this study, we used inductively coupled plasma mass spectrometry (ICP-OES) to evaluate the $\mathrm{PM}_{2.5}$ bound elemental composition. Average indoor $\mathrm{PM}_{2.5}$ concentrations were 94.24 and $42.07 \mu \mathrm{g} / \mathrm{m}^{3}$ in residential and city centers for the winter, and 12.06 and $23.51 \mu \mathrm{g} / \mathrm{m}^{3}$ for the summer period, respectively. In the $\mathrm{PM}_{2.5}$ samples, high concentrations of ambient elements were observed for $\mathrm{Ca}, \mathrm{Al}, \mathrm{K}, \mathrm{Zn}$, and $\mathrm{Pb}$. The concentration of toxic heavy metals such as $\mathrm{Pb}$ was 1.4 times higher than the Mongolian National Standard (MNS 4585:2016, which is $\left.1 \mu \mathrm{g} / \mathrm{m}^{3}\right)$. In conclusion, the seasonal variation of the elements' concentrations mostly depended on consumption, such as coal and wood consumption (W/S $>1$ ). Crustal matter elements depended on dusting and vacuuming activities $(\mathrm{W} / \mathrm{S}<1)$. In addition to elements, there are other air pollutants in indoor that should be identified and quantified to estimate the health effects due to indoor air pollution, such as elemental carbon (EC) and organic compounds. Thus, it is warranted to further study the levels of air pollutants in indoor, especially in the residential area in Ulaanbaatar.

Keywords: air pollution, fine particulate matter, indoor and outdoor housing, elemental composition, indoor stove, clean fuel, lead.
\end{abstract}

\section{INTRODUCTION}

Mongolia's population reached 3.1 million in 2016 [1], one of the least densely populated countries in the world, yet its two-thirds live in the capital, Ulaanbaatar [2]. According to Volodya et al., the main reasons for the inflow of people to the capital are environmental and economic problems. Increased anthropogenic disturbances such as mining, overgrazing, pasture land, inappropriate usage of crop lands, and deforestation have caused extreme soil destruction, intensified land degradation, and frequent sand storms [2]. Several of Ulaanbaatar's current socio-economic issues, especially environmental issues, are closely related to the impact from that inflow of people. Due to the housing deficit, most people that move to Ulaanbaatar have become residents of what is known as the residential area (Ger District). The ger district is home to approximately 736,000 residents. Ger districts, consisting of gers (Mongolian yurt) and other dwellings such as houses made of brick or wood, are distributed mainly in the northern valleys and western suburbs around the urban area (marked in yellow in Fig. 1). For heating and cooking, each household living in gers and houses uses coal and wood [3]. Most of the coal used in the ger district are not treated and emit a large amount of air pollutants compared to treated coal. In the ger district, there are 
two prominent dwelling types: ger and house. Houses are generally constructed from wood or brick. It is common for plots to host more than one household, which often leads to disputes regarding the redevelopment of ger areas to apartment blocks. It is generally agreed that one of the major sources of PM in Ulaanbaatar is the burning of coal and wood in individual residences in ger area [3]. As at 2015, there were 184,000 stoves and 3,341 hot water boilers used to heat these households in the ger district and raw untreated coal was the main fuel source for the stoves and hot water boilers. Ger district households consume approximately 800,000 metric tons of raw coal annually [4]. The vast majority of gers and houses in periurban areas are heated with raw coal lit by small amounts of wood in small chimney stoves, while apartment households in outside of the ger district almost exclusively employ clean indoor use (CIU) heat that creates no indoor emissions. Therefore, Ulaanbaatar faces a challenge to ban coal consumption and promote the use of processed coal and clean fuels to mitigate air pollution. The geographical characteristics and regional climate are also not favorable for air quality management in Ulaanbaatar. Ulaanbaatar is located in a basin surrounded by mountains at high altitude in $47^{\circ} 55^{\prime} 16.4^{\prime \prime} \mathrm{N}$ and $106^{\circ} 55^{\prime} 6.8^{\prime \prime} \mathrm{E}$ [5] which leads to a long and cold winter. Those unique geographical conditions provide suitable conditions for the formation of thick inversion layers and low mixing height in winter. According to Wang and Kai, maximum mixing height was below $500 \mathrm{~m}$ and thickness of inversion layer was 500 to $700 \mathrm{~m}$ in winter and emphasized that temperature inversion layer became thicker and stronger in winter (from September to January). That low mixing height, thick inversion layer forming a stable atmosphere, and continuous emitting air pollutants which resulted in severe particulate pollution.

Due to air pollution, pneumonia is leading among the respiratory diseases making up $20.2 \%$ of the patient population and it is especially high among children under 5 years old, making $70.9 \%$ of patients [8]. The Mongolian government for the first time has decided to ban the use of raw coal in Ulaanbaatar in 2018. According to the Government resolution No. 62 of 2018 [9], the use of raw coal has been banned since 15 May 2019, except entities and organizations that provide electricity and heat in the territory of Songino Khairkhan and Bayankhoshuu districts of Ulaanbaatar. Household indoor air quality can directly affect the health conditions of people dwelling in the home. However, there are only a few studies on the indoor air quality in ger [10], [11]. Furthermore, these studies were limited to one district in winter time. It is important to understand the relationship between the outdoor and indoor air quality to develop effective air quality management directions. Moreover, it is important to understand the different air quality characteristics depending on the household types, ger, house, and apartment. These differences combined with variations in outdoor particle infiltration between building types likely result in substantially different indoor concentrations between them. Indoor concentrations of $\mathrm{PM}_{2.5}$ should be estimated by housing type, household heating source, presence of second-hand tobacco smoke (SHS), and season.

The overall objective of this study is to understand the PM pollution in a household in Ulaanbaatar. To do that: (1) $\mathrm{PM}_{2.5}$ samples in both indoor and outdoor sites were collected at both residential and downtown district with different household types; (2) concentrations of their elemental species were analyzed; and (3) major sources of the observed elements were identified. To our knowledge, this is the first study in Mongolia to simultaneously analyze both indoor and outdoor concentrations of elements and their relationship.

\section{STUDY AREA}

This study was conducted in two areas in Ulaanbaatar, Mongolia, and in each area both indoor and outdoor sampling were carried out. Ulaanbaatar is divided into nine districts, each 


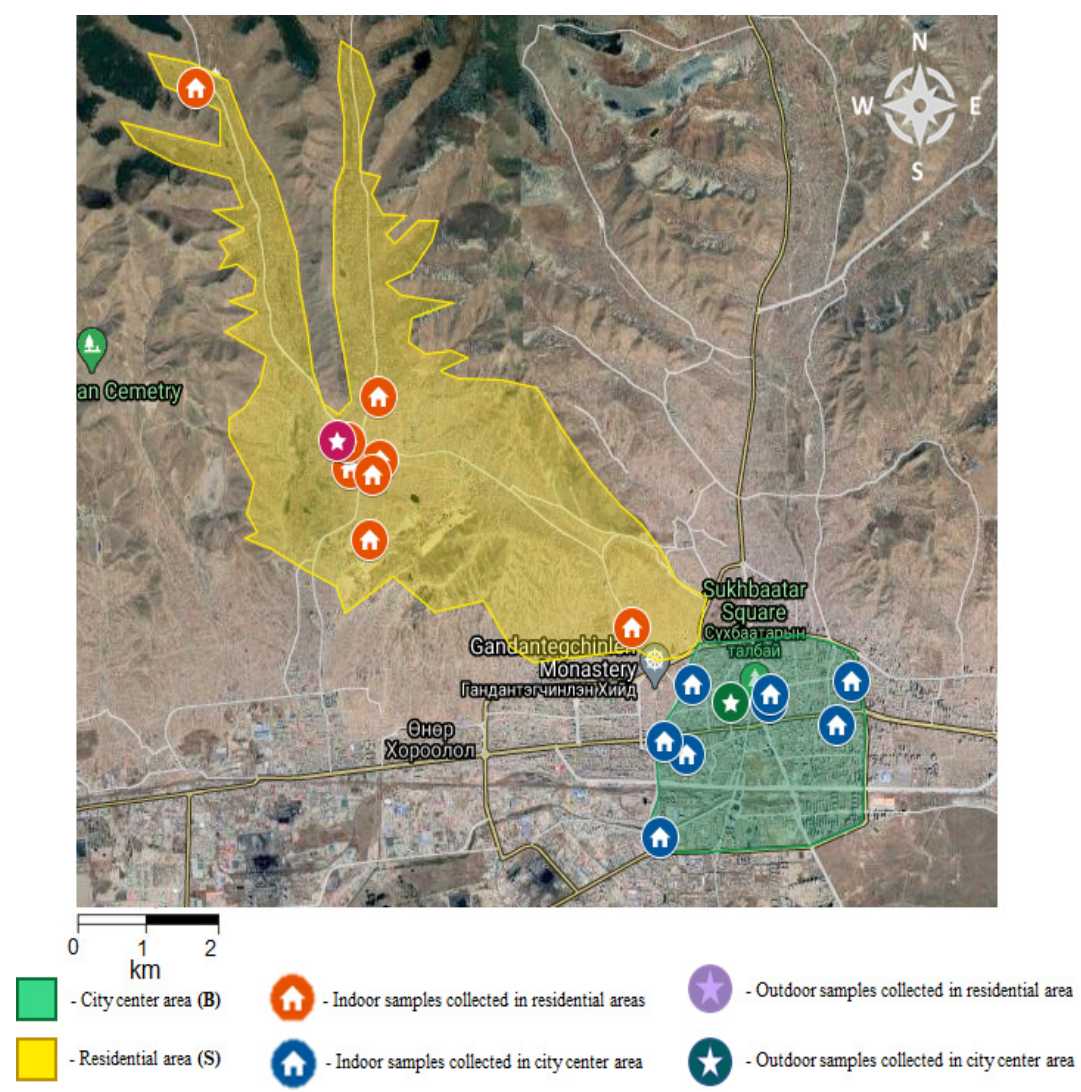

Figure 1: Indoor and outdoor PM sampling points in Songinokhairkhan (S: ger area, colored in yellow), and Bayanzurkh (B: city center, colored in green) districts in Ulaanbaatar. (Source: Modified from Google Maps.)

of which is subdivided into subdistricts (khoroo). There are a total of 121 khoroo. As shown in Fig. 1, the study areas are Songinokhairkhan (residential area, denoted S), and Bayanzurkh (city center, denoted B) districts. Songinokhairkhan is located in northeast part of Ulaanbaatar and one of the biggest districts by area in Ulaanbaatar and contains ger district. Bayanzurkh district is located in the center of the city and has a high population density ( 272 persons per $\mathrm{km}^{2}$ ) [12]. Demographical information on the sampling areas are given in Table 1. The $\mathrm{PM}_{2.5}$ sampling was performed between 2 December and 9 March (winter) 2019 and between 28 June and 28 August (summer) 2020 to evaluate the differences between summer and winter concentrations of air pollutants. We measured concentrations in three household types, ger, house and apartment. The locations of the sampling points are shown in Fig. 1. The selection of the sampling points was made in consideration of the possible domestic heating sources and a comparison was made by selecting sampling points in both residential (S) and city center (B) areas. Residential sampling area is affected mainly by domestic heating emissions and by traffic. It is expected that the city center sampling area is less affected by heating related emissions. In winter, samples were collected at four houses and two gers in S and four apartments in B, respectively. In summer, samples were collected at 
three houses in S and five apartments in B, respectively. Since in summer there is no heating in gers, sampling was not carried out in the ger. The participating households were recruited by doctors at a primary healthcare center. Outdoor samplings were carried out at the APRD five monitoring sites at S and NAMEM B districts, respectively, both of which were operated by Government.

Table 1: Demographical information of the sampling areas [12].

\begin{tabular}{lccccc}
\hline Sampling sites & Household & Population & Apartment & House & Ger \\
\hline $\begin{array}{l}\text { Songinokhairkhan district } \\
\text { (S, residential area) }\end{array}$ & 5,200 & 327,580 & 886 & 1,951 & 1,900 \\
\hline $\begin{array}{l}\text { Bayanzurkh district } \\
\text { (B, city area) }\end{array}$ & 4,274 & 361,689 & 4,274 & - & - \\
\hline
\end{tabular}

In addition to the sampling, a survey was carried out to identify the indoor characteristics such as the type and amount of fuel used, frequency of fuel addition, the number of meals cooked, the number of family members and indoor smoking status during the study period. Specially designed housing questionnaires were collected from members of each household (aged over 11 years old). The survey was collected from a total of 119 people. In addition, major vitals such as blood pressure, heart rate, and blood oxygen levels were measured in these 119 individuals during indoor measurements. The survey was conducted through a cross-sectional design covering two districts (Table 1) of the Ulaanbaatar city. Data analysis was based on measurements conducted in a total of nine ger and houses in $\mathrm{S}$ district and nine apartments in B district and the survey result is shown in Table 1.

\subsection{Particulate matter sampling}

The indoor particle concentration in each household was measured using two different $\mathrm{PM}_{2.5}$ sampling instruments for 8 hours (10:00-18:00) during daytime and 12 hours during night time. Each household was measured once in each season. Two samplers were used for indoor sampling. For daytime sampling, the MiniVol TAS Tactical Air Sampler was placed in the center of each microenvironment on a table roughly $1.5 \mathrm{~m}$ from the floor level in order for the sampling to occur within the breathing zone of a seated individual. Due to the noise problem, a real-time measuring Portable AsLung V2 sampling instrument based on lightscattering technology was used during night-time. Thus, indoor elemental data are for the daytime data only. In addition to $\mathrm{PM}_{2.5}$, temperature, pressure, and moisture were also recorded hourly. The Partisol ${ }^{\mathrm{TM}} 2000 \mathrm{i}$ was used for collection of outdoor $\mathrm{PM}_{2.5}$. The outdoor samples were sampled for $23 \mathrm{~h}$ at the same day as the indoor samples. The filter cartridge was equipped with a $2 \mu \mathrm{m}$ pore sized $47 \mathrm{~mm}$ PTFE membrane disk filter (Teflon ${ }^{\circledR}$ with support ring, MTL) with integrated filter collection. Samples were weighed by a six-digit electronic microbalance (Ba-C, BIOBASE, China). Quality control in filter weighting was ensured by using appropriate laboratory and field blanks. Each filter was weighed at least three times to ensure that the difference of each measurement was within $0.1 \mathrm{mg}$. After weighing, the sampled filters were stored in a refrigerator at $4^{\circ} \mathrm{C}$ for subsequent analysis.

\subsection{Elemental analysis}

External calibration was performed before and after analysis. Before the analysis, the samples are divided into four equal parts and one piece has been used for elemental analysis. Then 34 
elements were analyzed by inductively coupled plasma mass spectrometry (ICP-OES), but 18 elements were detected (see Table 3). Sixteen elements (As, Be, Bi, Ga, Mo, Ni, Re, Sb, $\mathrm{Se}, \mathrm{Ta}, \mathrm{Th}, \mathrm{U}, \mathrm{V}, \mathrm{Y}, \mathrm{Yb}, \mathrm{Zr}$ ) were below limit of detection (LoD) and not reported in this study. A quarter of PTFE filters were used for each sample digestion and placed $40 \mathrm{ml}$ vials. The filter was extracted with $20 \mathrm{~mL} \mathrm{2 \%}$ nitric acid for 30 minutes six times under heated $\left(69^{\circ} \mathrm{C}\right)$ ultrasonication. The heated digestion was cooled down to room temperature. Then the digestions were filtrated on $0.45 \mu \mathrm{m}$ pore size filter (MCE, $25 \mathrm{~mm}$ syringe filter, JetBiofil) and the solution became ready for analysis. The chemical compositions of the $\mathrm{PM}_{2.5}$ filter samples were analyzed using ICP/OES (iCAP7000, Thermo Fisher Scientific, USA). The certified reference materials were used for calibration purposes in the analyses of elements. Eleven certified reference materials were used for calibration purposes in the analyses of major elements such as: GNM-SET-001-0-5, GNM-SET-002-0-3, GNM-SET-003-0-3, GNM-SET-004-0-4, GNM-SET-014-0-4, GNM-SET-015-0-4, GNM-SET-030-0-3 and GNM-M33198. Analysis of blank samples, determination of detection limits, and recovery tests were also performed for the quality control of analytical procedures (MNS 17:025) used in analysis studies. The LoD for an element is determined as three times the standard deviation of 10 analyses of the blank sample.

\subsection{Statistical analysis}

The varimax rotated factor analysis (FA) was performed separately on indoor and outdoor datasets for households to show possible element sources for $\mathrm{PM}_{2.5}$. The factor analysis identifies groups of elements whose concentrations fluctuate together from one sample to another and separates those elements into factors. Elements were included in FA only if the observations had data for at least $30 \%$ of the samples. Values reported below the LoD were included in the analysis to create the largest matrix possible. In this study, one-half of the LoD of elements was used for the treatment of missing values.

\section{RESULTS AND DISCUSSION}

\subsection{Indoor and outdoor $\mathrm{PM}_{2.5}$ characteristics}

Health effects of ambient $\mathrm{PM}_{2.5}$ have been widely reported in terms of mortality and morbidity of cardiopulmonary diseases, the prevalence of respiratory symptoms, and hospital admission. Smoking rates in Mongolia are among the highest in the world.

Recent nationwide bans on public indoor smoking suggest indoor SHS may only make considerable contributions to exposure in personal, private indoor environments. Indoor concentration estimates thereby conservatively assume that SHS occurred only indoors at home and thus contributions from SHS were applied only to night-time indoor concentration estimates. For simplicity and due to limited information on Mongolian workplace environments, the concentration profiles of the indoor environments in which the population spends their time away from home were assumed the same as those of their home indoor environments [16]. The 24 hour profile of $\mathrm{PM}_{2.5}$ both indoor, outdoor in winter and summer summarized in Fig. 2. In winter $\mathrm{PM}_{2.5}$ concentration increase at 6:00 a.m. and high concentration were observed from 10:00 a.m. to 11:00 a.m. in both indoor and outdoor. The concentration decreased continuously from 12 p.m. to 4 p.m., increased again beginning at 4 p.m. and remained high until after 3 a.m., when it decreased slowly until 6 a.m. Highest and lowest average 1 hour average concentrations both indoor and outdoor were $177 \mu \mathrm{g} / \mathrm{m}^{3}$ at 11:00 a.m. and $270 \mu \mathrm{g} / \mathrm{m}^{3}$ 10:00 a.m. Ger areas tended to have higher hour average 
concentration than city center. Outdoor $\mathrm{PM}_{2.5}$ concentrations much higher than indoor during winter. In summer $\mathrm{PM}_{2.5}$ concentration increase at 12:00 p.m. and highest daytime concentration were observed at 2 p.m. indoor and high until 12 a.m. At 2:00 a.m., unexpected $\mathrm{PM}_{2.5}$ high concentration observed in both indoor and outdoor. Highest and lowest average 1 hour average concentrations both indoor and outdoor were $59 \mu \mathrm{g} / \mathrm{m}^{3}$ at 2:00 a.m. and $11 \mu \mathrm{g} / \mathrm{m}^{3}$ 11:00 a.m. City center tended to have higher hour average concentration than ger area. Indoor $\mathrm{PM}_{2.5}$ concentrations much higher than outdoor during summer.
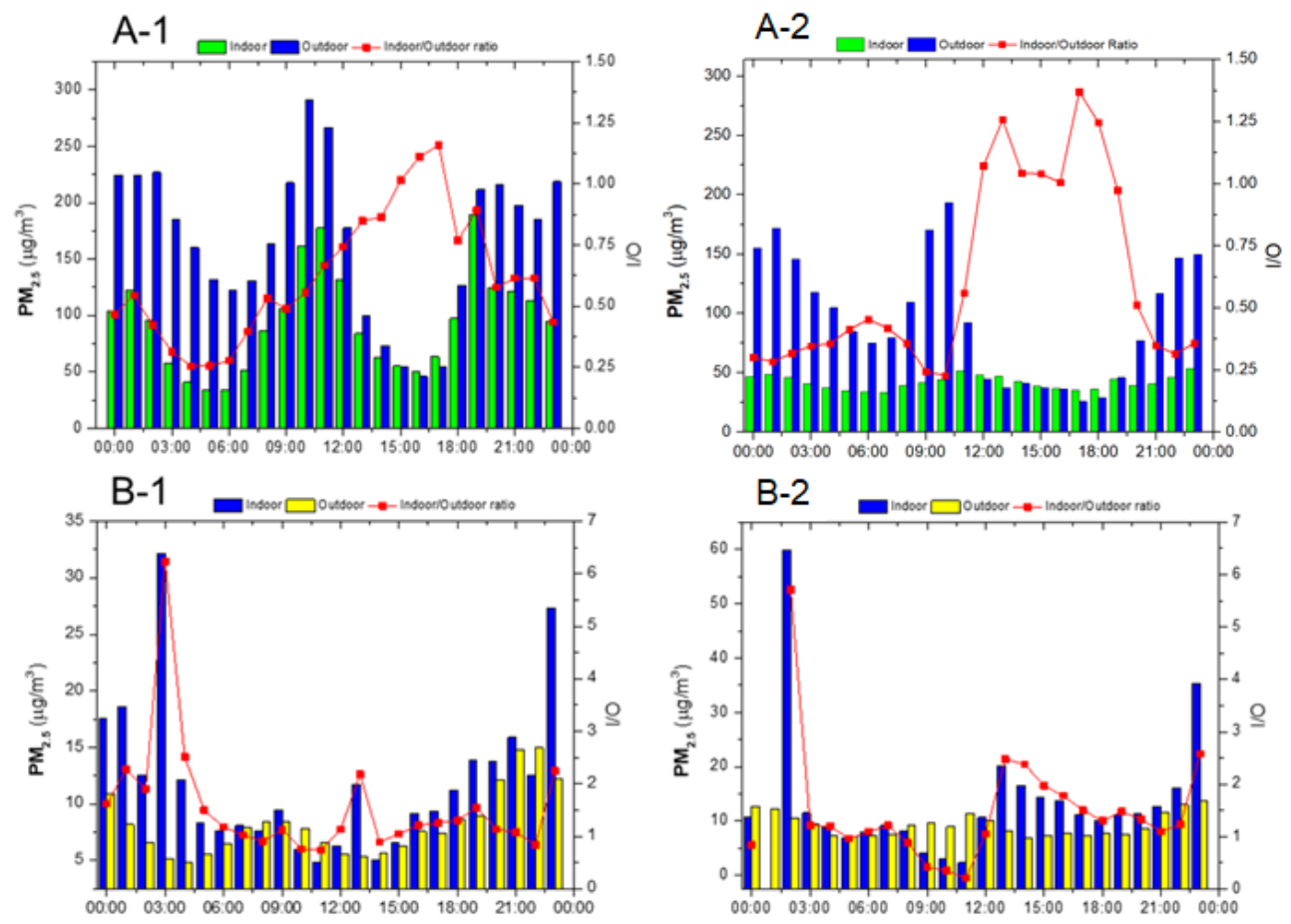

Figure 2: Indoor and outdoor $24 \mathrm{~h}$ profiles of $\mathrm{PM}_{2.5}$ (A-1 Winter ger area, A-2 Winter city center, B-1 Summer ger area, B-2 Summer city center).

The observed mass concentration of $\mathrm{PM}_{2.5}$ in each type of houses is summarized in Fig. 3. As shown in Fig. 3, the 24 hour average $\mathrm{PM}_{2.5}$ concentrations were $95.8-44.1 \mu \mathrm{g} / \mathrm{m}^{3}$ in houses, 93.4-42.4 $\mu \mathrm{g} / \mathrm{m}^{3}$ in gers and $42.1-6.29 \mu \mathrm{g} / \mathrm{m}^{3}$ in apartments. The $\mathrm{PM}_{2.5}$ concentrations of households living in gers and houses in ger areas (S) were 3.7-3.8 times higher than the WHO recommended concentration, and 1.8-1.9 times higher than the Mongolian national standard (tolerance level). For those living in apartments downtown, it was 1.7 times higher than the recommended concentration and less than the allowable concentration of the Mongolian national standard. For each element, generally the concentrations were higher in houses and gers than apartments as shown in Fig. 2. 


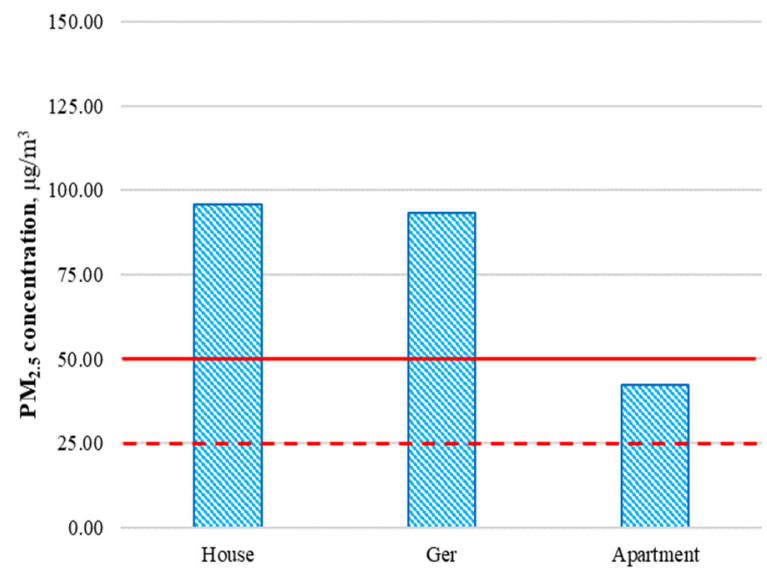

Figure 3: 24 hour average concentration of indoor $\mathrm{PM}_{2.5}$ by type of housing (Red line: Mongolian national standard, MNS 4585:2016. Dashed red line: WHO Air Quality Guideline).

\subsection{Elemental composition in $\mathrm{PM}_{2.5}$}

The mass concentrations of $\mathrm{PM}_{2.5}$ were $95.8-44.1 \mu \mathrm{g} / \mathrm{m}^{3}$ in houses, $93.4-42.4 \mu \mathrm{g} / \mathrm{m}^{3}$ in gers, and $42.1-6.29 \mu \mathrm{g} / \mathrm{m}^{3}$ in apartments. In the $\mathrm{PM}_{2.5}$ samples, high concentrations of ambient elements as shown in Fig. 4, were observed for Ca $\left(28.6 \pm 67.1 \mu \mathrm{g} / \mathrm{m}^{3}\right)$, Al $(4.238 \pm$ $\left.1.116 \mu \mathrm{g} / \mathrm{m}^{3}\right), \mathrm{K}\left(3.808 \pm 1.663 \mu \mathrm{g} / \mathrm{m}^{3}\right), \mathrm{Zn}\left(1.831 \pm 3.148 \mu \mathrm{g} / \mathrm{m}^{3}\right)$ and $\mathrm{Pb}(1.411 \pm$ $\left.1.441 \mu \mathrm{g} / \mathrm{m}^{3}\right)$. The concentrations of toxic heavy metals such as $\mathrm{Pb}$ was 1.4 higher than the Mongolian National Standard (MNS 4585:2016, which is $1 \mu \mathrm{g} / \mathrm{m}^{3}$ ). Seasonal variations of the mean and standard deviation of the element concentrations in the indoor and outdoor samples in winter and those in the indoor samples in summer are shown in Table 3 along with the seasonal ratio values, i.e., the ratio of the concentration in winter to that of summer (W/S). The concentrations of crustal elements such as $\mathrm{Ca}$ and $\mathrm{Mg}$ were lower in winter compared to that in summer. Generally, the seasonal variation of the elements' concentrations mostly depended on consumption, such as coal and wood consumption (W/S $>1)$. Crustal matter elements depended on dusting and vacuuming activities $(\mathrm{W} / \mathrm{S}<1)$. As shown in Table 3 , the concentration patterns are similar for both summer/winter and indoor/outdoor conditions. When the trace element concentrations were analyzed, the highest concentrations were found to be $\mathrm{Ca}, \mathrm{Al}, \mathrm{K}$, and $\mathrm{Ba}$ and the lowest concentrations were found to be $\mathrm{Cr}, \mathrm{Co}$, and $\mathrm{Cu}$ in winter. The highest concentrations were found to be $\mathrm{Ca}, \mathrm{Al}, \mathrm{K}$, and $\mathrm{Zn}$ and the lowest concentrations were found to be $\mathrm{Cr}$, $\mathrm{Ti}$ and $\mathrm{Mn}$ in summer. Comparisons of the elemental concentrations measured in residential (S) and city center (B) in winter and summer periods are seen in Fig. 4. With intense combustion of coal and wood in the gers and housed in residential area (S) compared to the apartments in city center (B) where coal or wood combustion activities were negligible, the concentrations of most elements in $\mathrm{S}$ were higher than B. In summer, as shown in Fig. 4, the pattern was reversed.

The composition of the elements in the indoor air has been extensively studied in other countries. However, in 2007, the first major study of indoor air quality in Mongolia determined the element concentration in the aerosols. Table 2 compares the previous study results from the United States, Qatar, China, Austria, and India. 


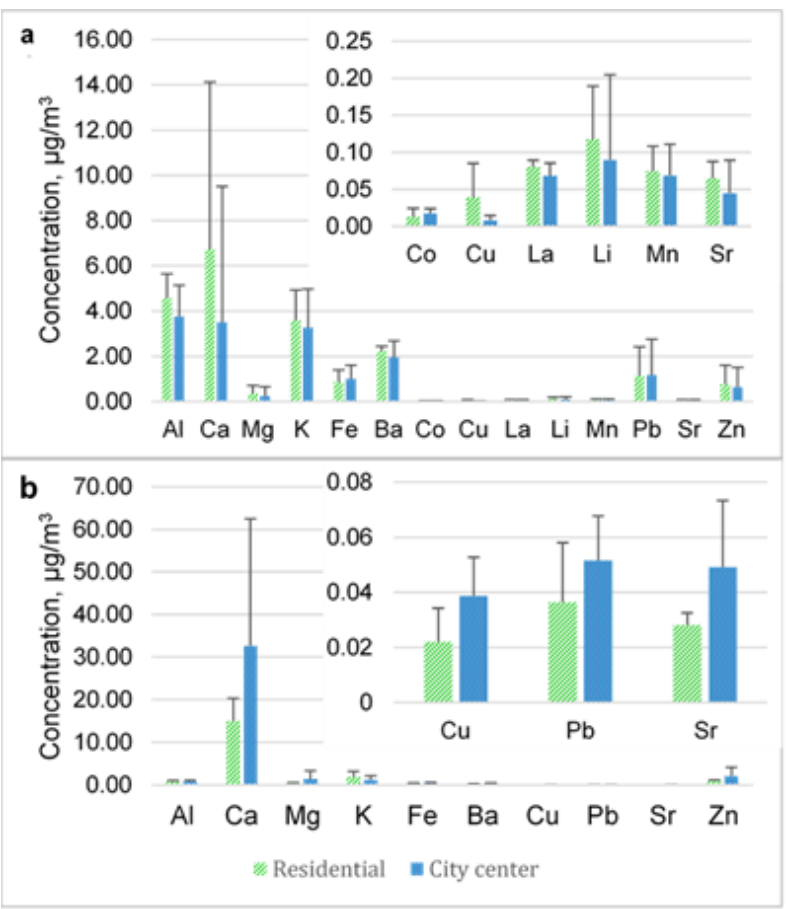

Figure 4: Mean concentrations and standard deviations of the elements in indoor samples in residential (S) and city center (B) and during (a) winter; and (b) summer $\left(\mu \mathrm{g} / \mathrm{m}^{3}\right)$.

Table 2: Comparison of heavy metal concentration with the results of other researchers.

\begin{tabular}{lcccccccl}
\hline $\begin{array}{l}\text { Research } \\
\text { object }\end{array}$ & \multicolumn{9}{c}{ Concentration, ng/m } \\
\cline { 2 - 9 } & $\mathrm{Co}$ & $\mathrm{Ni}$ & $\mathrm{Cu}$ & $\mathrm{Zn}$ & $\mathrm{Cr}$ & $\mathrm{Cd}$ & $\mathrm{Pb}$ & \\
\hline $\begin{array}{l}\text { House } \\
\text { (winter) }\end{array}$ & $\mathbf{2 0}$ & $<\mathbf{L o D}$ & $\mathbf{4 2}$ & $\mathbf{1 8 3 1}$ & $\mathbf{1 2}$ & $\mathbf{7 6}$ & $\mathbf{1 4 1 1}$ & This study \\
\hline $\begin{array}{l}\text { House } \\
\text { (summer) }\end{array}$ & $<\mathbf{L o D}$ & $<\mathbf{L o D}$ & $\mathbf{8 9}$ & $\mathbf{4 4 2 0}$ & $\mathbf{4 5}$ & $<\mathbf{L o D}$ & $\mathbf{1 1 3}$ & \\
\hline House & - & 4 & 21 & 77 & - & - & 53 & Shanghai, China \\
\hline Apartment & 0.23 & 4.55 & 6.92 & 19.5 & 4.3 & 0.16 & 6.06 & Doha, Qatar [13] \\
\hline House & - & - & - & - & - & 0.57 & 23.9 & $\begin{array}{l}\text { Wien, Austria } \\
\text { [14] }\end{array}$ \\
\hline House & 16.3 & 27 & 33 & 2810 & 7.1 & 9.3 & 821 & Deli, India [15] \\
\hline Standards & & & & & & & & \\
\hline MNG & & & & & & & 1000 & MNS 4585:2016 \\
\hline WHO & & 1000 & & & & 5 & 1000 & WHO, 2000 \\
\hline US EPA & & 20 & & & & 5 & 150 & US EPA, 1997 \\
\hline
\end{tabular}

As shown in Table 2, the concentrations of heavy metals in the indoor air vary depending on the lifestyle of the country and the pollution of the environment. In the United States, Austria, and Qatar, where coal combustion was rarely used in the home, the heavy metal concentration is below the WHO standards. On the contrary, in China and India, which use 
raw coal, the heavy metal concentration exceeds the WHO standards. Our study found a $\mathrm{Pb}$ concentration of $1,411 \mathrm{ng} / \mathrm{m}^{3}$ and a $\mathrm{Zn}$ concentration of $1,831 \mathrm{ng} / \mathrm{m}^{3}$ in winter, which is close to the $\mathrm{Pb}$ concentration of $821 \mathrm{ng} / \mathrm{m}^{3}$ and the $\mathrm{Zn}$ concentration of $2,810 \mathrm{ng} / \mathrm{m}^{3}$, the results of a study conducted in India. India has a high concentration of outdoor air pollution and a raw indoor environment, which is similar to Ulaanbaatar, so the results are likely to be similar. The concentration of 20 elements in $\mathrm{PM}_{2.5}$ was determined to be 1.5 times higher than the MNS $\left(1,000 \mathrm{ng} / \mathrm{m}^{3}\right)$ in winter, 5.1 times higher than the US EPA standard $\left(5 \mathrm{ng} / \mathrm{m}^{3}\right)$ in summer and winter. The nickel (Ni) concentration increased 1.8 times higher than the US standard $\left(20 \mathrm{ng} / \mathrm{m}^{3}\right)$. Carcinogenic heavy metals such as cadmium, lead, and nickel may have been contaminated by human activities.

The concentrations in houses were slightly higher than those in gers as shown in Fig. 5, but the difference was small. These suggest that the combustion of coal and wood in houses and gers in residential area (S) was the dominant factor, which determined the concentration of $\mathrm{PM}_{2.5}$ and elements' concentration in the homes at both residential area (S) and city center (B).

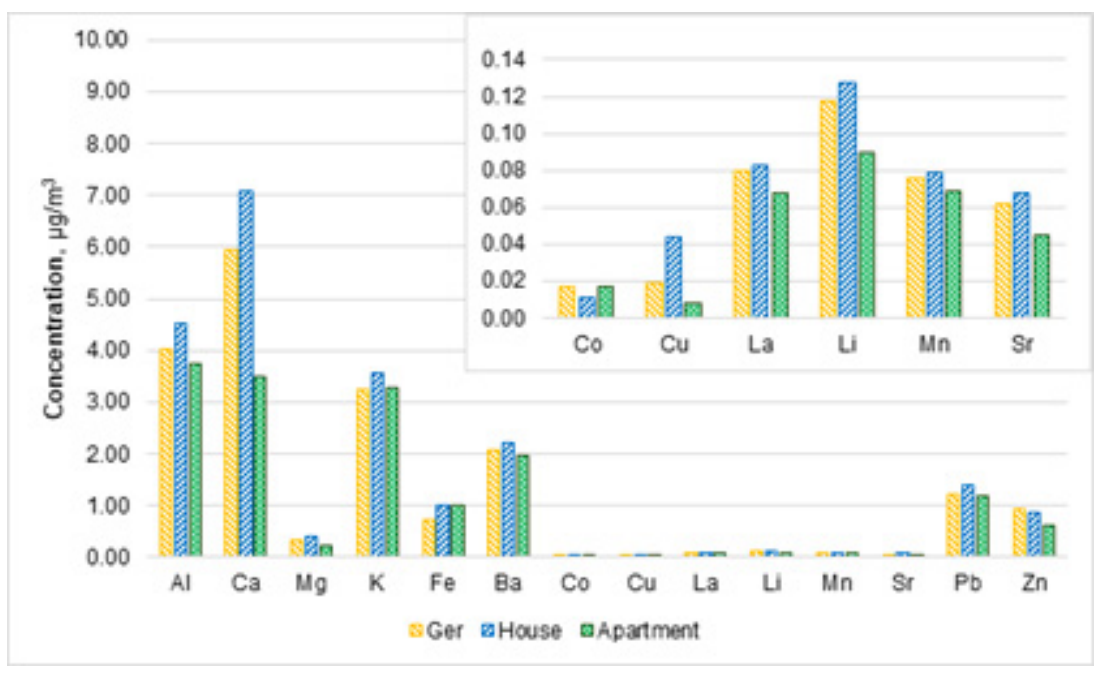

Figure 5: Elemental composition by different housing.

\subsection{Factor analysis: Estimation of heavy metal sources}

The concentration of any pollutant in indoor depends on the balance between its source and sink. Table 3 shows indoor and outdoor varimax rotating factor analysis datasets for homes to identify possible heavy metal sources in winter. The eigenvalue was set to 1.0 as a threshold limit on the number of extracted factors. Factor loadings equal to or greater than 0.3 are presented because those $<0.3$ were considered insignificant. The chemicals introduced with ambient air depend on the location and leakiness of the houses, gers and apartments. Four factors were extracted from the indoor data which explained about $95.09 \%$ of the total variance, with the first factor (F1 indoor) accounting for $56.56 \%$, the second (F2 indoor) for $16.97 \%$, the third (F3 indoor) for $11.41 \%$ and the fourth (F4 indoor) for $5.97 \%$. The F1 indoor factor shows high loadings for $\mathrm{K}, \mathrm{Fe}, \mathrm{Cd}, \mathrm{Co}, \mathrm{Li}, \mathrm{Mn}, \mathrm{Pb}$ and moderate loadings for $\mathrm{Zn}, \mathrm{Sr}$. All the elements in the first factor except Fe, Sr, Mn are mostly from 
combustion of coal or wood. The presence of Fe, Mn suggests the mixing of some fly ash components into this factor. The first factor probably represents coal and wood combustion.

Table 3: Factor analysis of indoor and outdoor in winter.

\begin{tabular}{|c|c|c|c|c|c|c|c|c|}
\hline \multirow{2}{*}{ Components } & \multicolumn{4}{|c|}{ Indoor } & \multicolumn{4}{|c|}{ Outdoor } \\
\hline & F1 & F2 & F3 & F4 & F1 & F2 & F3 & F4 \\
\hline $\mathrm{Al}$ & & 0.05 & 0.82 & 0.24 & 0.77 & 0.40 & 0.41 & \\
\hline $\mathrm{Ca}$ & 0.36 & 0.93 & & 0.02 & 0.78 & & 0.17 & 0.26 \\
\hline $\mathrm{Mg}$ & 0.49 & 0.86 & & & 0.91 & & 0.08 & \\
\hline $\mathrm{K}$ & 0.84 & 0.46 & & & 0.11 & 0.63 & & 0.72 \\
\hline $\mathrm{Fe}$ & 0.83 & 0.47 & & 0.05 & 0.62 & & 0.71 & 0.07 \\
\hline $\mathrm{Ba}$ & & 0.02 & 0.99 & 0.04 & 0.30 & 0.38 & 0.75 & \\
\hline $\mathrm{Cd}$ & 0.89 & 0.32 & & & & & & \\
\hline Co & 0.78 & 0.21 & & & & & & \\
\hline $\mathrm{Cr}$ & & & & 0.89 & & & 0.94 & \\
\hline $\mathrm{Cu}$ & & 0.45 & 0.20 & 0.82 & & 0.86 & & 0.05 \\
\hline $\mathrm{La}$ & 0.08 & & 0.78 & & & 0.93 & 0.23 & \\
\hline $\mathrm{Li}$ & 0.90 & 0.31 & 0.06 & & 0.13 & & 0.08 & 0.31 \\
\hline $\mathrm{Mn}$ & 0.82 & 0.54 & & & 0.92 & 0.13 & 0.17 & 0.20 \\
\hline $\mathrm{P}$ & 0.33 & & & & 0.82 & 0.02 & & \\
\hline $\mathrm{Pb}$ & 0.91 & 0.33 & & & & & & 0.85 \\
\hline $\mathrm{Sr}$ & 0.56 & 0.82 & 0.08 & & 0.82 & 0.34 & 0.09 & 0.39 \\
\hline $\mathrm{Ti}$ & 0.27 & 0.95 & & 0.04 & 0.94 & & 0.22 & 0.11 \\
\hline $\mathrm{Zn}$ & 0.49 & 0.86 & & & 0.42 & & & 0.79 \\
\hline Eigenvalue & 10.54 & 3.05 & 2.05 & 1.08 & 5.81 & 3.69 & 2.41 & 2.39 \\
\hline$\%$ of Variance & 58.56 & 16.97 & 11.41 & 5.97 & 36.34 & 23.08 & 15.05 & 14.96 \\
\hline Cumulative \% & 58.56 & 75.53 & 86.94 & 92.91 & 36.34 & 59.41 & 74.46 & 89.43 \\
\hline $\begin{array}{c}\text { Possible } \\
\text { source type }\end{array}$ & Com- $2^{\mathrm{a}}$ & Ash & $\operatorname{Traff}^{\mathrm{c}}$ & Act- $C^{d}$ & Dust & Pet-C $C^{b}$ & $\operatorname{Traff}^{\mathrm{c}}$ & Com- $2^{\mathrm{a}}$ \\
\hline
\end{tabular}

The F2 indoor factor shows high loadings for $\mathrm{Ca}, \mathrm{Mg}, \mathrm{Sr}, \mathrm{Ti}, \mathrm{Zn}$, moderate loading for $\mathrm{K}$, $\mathrm{Fe}, \mathrm{Cu}, \mathrm{Mn}$. All elements are mostly from crustal components except for K, Zn. [17], [18] studies suggested that $\mathrm{Zn}, \mathrm{Cu}, \mathrm{Mn}, \mathrm{Fe}$ are associated with industrial processes. In our study, there are no factories in our study area and high loadings of crustal matter components seem to be $\mathrm{Zn}, \mathrm{Cu}, \mathrm{Mn}, \mathrm{Fe}$ mostly from fly ash in winter. The F3 indoor factor shows high loadings of Al, Ba, La. There is a high loading of barium (0.99) in F3 indoor that indicates a traffic emission source, especially brake and tyre depreciation [19]. The F4 indoor factor shows high loadings for $\mathrm{Cr}, \mathrm{Cu}$, and those elements are mostly from cooking activities. In outdoor, four factors were extracted which explained about $89.43 \%$ of the total variance, with the first factor (F1 outdoor) accounting for $36.34 \%$, the second factor (F2 outdoor) for $23.08 \%$, the third factor (F3 outdoor) for $15.05 \%$ and the fourth factor (F4 outdoor) accounting for $14.96 \%$ in outdoor $\mathrm{PM}_{2.5}$. The $\mathrm{F} 1$ outdoor factor had high loads for $\mathrm{Mg}, \mathrm{Al}, \mathrm{Ca}, \mathrm{Ti}, \mathrm{Mn}, \mathrm{P}$ and $\mathrm{Sr}$. All elements in this factor area were most often found in crustal matter. The F2 outdoor factor had high loadings of $\mathrm{La}, \mathrm{Cu}, \mathrm{K}$ and moderate loading of $\mathrm{Ba}, \mathrm{Al}, \mathrm{Sr}$. $\mathrm{Ba}, \mathrm{Cu}, \mathrm{La}$ are known to be the markers for traffic emission and, especially, $\mathrm{Cu}$ and La were known to be mainly from vehicle exhaust. The F3 outdoor factor was similar to the F3 indoor factor and had additionally $\mathrm{Fe}, \mathrm{Al}$ and $\mathrm{Ti}$ which could be explained by road dust resuspension mixed with vehicular emission [20]. The F4 outdoor factor had high loading for $\mathrm{Pb}, \mathrm{Zn}, \mathrm{K}$ and moderate 
loadings for $\mathrm{Sr}$, Li. The main source of $\mathrm{Pb}$ is known to be combustion, especially coal combustion, and $\mathrm{K}$ comes mostly from biomass burning (wood, incense etc). This source was also mixed with fly ash elements $\mathrm{Zn}, \mathrm{Sr}, \mathrm{Li}$ and suggested the combustion of coal and wood. Four factors were extracted from the summer indoor data, which explained about $89.96 \%$ of the total variance, with the first factor occupying $36.33 \%$, the second $29.25 \%$, the third $15.41 \%$ and the fourth $8.97 \%$ of the total variance. The first factor had high loading for $\mathrm{Ca}$, $\mathrm{Mg}, \mathrm{Sr}, \mathrm{Pb}, \mathrm{Mn}$ and moderate loadings for $\mathrm{Cu}$. First factor's elemental composition was most often found in the crustal matter (except $\mathrm{Pb}$ ).

The presence of $\mathrm{Pb}$ suggests the mixing of some anthropogenic components into this factor. The second factor elemental fractions are most often found in traffic exhaust and crustal matter.

Table 4: The factor analysis of indoor in summer.

\begin{tabular}{lcccc}
\hline \multirow{2}{*}{ Components } & \multicolumn{4}{c}{ Indoor } \\
\cline { 2 - 5 } & $\mathbf{F 1}$ & $\mathbf{F 2}$ & $\mathbf{F 3}$ & $\mathbf{F 4}$ \\
\hline $\mathrm{Al}$ & 0.08 & 0.78 & 0.55 & \\
$\mathrm{Ca}$ & 0.94 & & & \\
$\mathrm{Mg}$ & 0.92 & & & \\
$\mathrm{~K}$ & & 0.34 & 0.39 & 0.79 \\
$\mathrm{Fe}$ & 0.21 & 0.09 & 0.93 & 0.13 \\
$\mathrm{Ba}$ & & 0.94 & 0.24 & \\
$\mathrm{Co}$ & & & 0.05 & 0.93 \\
$\mathrm{Cr}$ & 0.34 & & & \\
$\mathrm{Cu}$ & 0.51 & 0.05 & 0.30 & \\
$\mathrm{Li}$ & & 0.94 & & 0.07 \\
$\mathrm{Mn}$ & 0.72 & & 0.37 & \\
$\mathrm{~Pb}$ & 0.80 & & 0.47 & 0.26 \\
$\mathrm{Sr}$ & 0.96 & 0.01 & 0.12 & \\
$\mathrm{Ti}$ & 0.29 & & & \\
$\mathrm{Zn}$ & 0.40 & & 0.32 & \\
\hline Eigenvalue & 5.45 & 4.39 & 2.31 & 1.34 \\
\% of Variance & $\mathbf{3 6 . 3 3}$ & $\mathbf{2 9 . 2 5}$ & $\mathbf{1 5 . 4 1}$ & $\mathbf{8 . 9 7}$ \\
$\mathrm{Cumulative} \mathrm{\%}$ & 36.33 & 65.57 & 80.99 & 89.95 \\
Possible source type & Act- $\mathrm{D}^{\mathrm{b}}$ & $\mathrm{Road}$ & $\mathrm{Ash}$ & Act-C \\
\hline a cooking activity; & & & & \\
b dusting activity. & & & &
\end{tabular}

The third factor had high loadings for $\mathrm{Al}, \mathrm{Fe}$ and moderately loadings for $\mathrm{K}, \mathrm{Mn}, \mathrm{Pb}, \mathrm{Zn}$ that is most often found in fly ash elemental composition in the indoor factor 2 . The fourth factor, the high loadings for Co and $\mathrm{K}$ are mostly from biomass burning [21]. Most residents (in a residential area) use wood for cooking in the warm season and the suggested factor 4 probably represents cooking activities.

\section{CONCLUSIONS}

Air quality in Ulaanbaatar is poor mainly due to the combustion of coal and wood in the residential area. To quantify and determine major sources of both indoor and outdoor concentrations of elements in ambient $\mathrm{PM}_{2.5}, \mathrm{PM}_{2.5}$ samples were collected in various housing types; ger and houses (dwelling made of wood or brick) where coal and wood are 
used for cooking and heating, and apartments (housing complexes with central heating) in summer and winter. Thirty-four elements were analyzed by using an ICP/OES, but the levels of 16 elements were below the LoD.

Generally, the seasonal variation of the elements' concentrations mostly depended on consumption, such as coal and wood consumption (W/S $>1)$. Crustal matter elements depended on dusting and vacuuming activities $(\mathrm{W} / \mathrm{S}<1)$. Concentration of toxic heavy metals such as lead $(\mathrm{Pb})$ was 1.4 times higher than the Mongolian national standard, $1 \mu \mathrm{g} / \mathrm{m}^{3}$ (MNS 4585:2016). It was found out that the concentrations of most elements in the residential area where coal and wood combustion activities were carried out were higher than the city center where these combustion activities were not carried out in winter. Compared with the results observed in other countries, the concentrations in Ulaanbaatar were higher than the countries with little coal or wood combustion in the home while comparable to the countries with coal and wood combustion activities in home.

Major factors affecting the elements' concentrations in both indoor and outdoor were studied by using the factor analysis method. Four factors were identified for both indoor and outdoor sources in winter. The dominant factor was coal and wood combustion for indoor, followed by the mixture of soil and fly ash, traffic and cooking. For outdoor, soil was the dominant factor, followed by traffic, a mixture of road dust and traffic resuspension, and coal and wood combustion. In summer, four factors were also identified for indoor soil, mixture of traffic and soil, mixture of soil and fly ash and cooking.

This study is the first study on the $\mathrm{PM}_{2.5}$ bound elemental compositions of indoor during winter and summer in Ulaanbaatar after the import of raw coal was banned in Ulaanbaatar. Thus, this study may provide valuable information of indoor air quality in Ulaanbaatar. In addition to elements, there are other air pollutants in indoor that should be identified and quantified to estimate the health effects due to indoor air pollution, such as elemental carbon (EC) and organic compounds. Thus, it is warranted to further study the levels of air pollutants in indoor, especially in residential area in Ulaanbaatar.

\section{ACKNOWLEDGEMENT}

This study is supported by the National Strategic Project of Fine Dust, Republic of Korea 2020-2021.

\section{REFERENCES}

[1] Mitchell, M.J., BTI 2018 country report: Mongolia. Asian Secur. Handb. Assess. Polit. Issues Asia-Pacific Reg. pp. 184-190, 2019.

[2] Volodya, E., Yeo, M.J. \& Kim, Y.P., Trends of ecological footprints and policy direction for sustainable development in Mongolia: A case study. Sustain., 10, 2018. DOI: $10.3390 /$ su10114026.

[3] Guttikunda, S.K. et al., Particulate pollution in Ulaanbaatar, Mongolia. Air Qual. Atmos. Heal., 6, pp. 589-601, 2013.

[4] Engel, D., Ulaanbaatar's Ger District Issues: Changes and Attitudes.

[5] Ganbat, G. \& Baik, J.-J., Wintertime winds in and around the Ulaanbaatar metropolitan area in the presence of a temperature inversion. Asia-Pacific J. Atmos. Sci., 52, pp. 309-325, 2016.

[6] Wang, M. et al., Meteorological factors affecting winter particulate air pollution in Ulaanbaatar from 2008 to 2016. Asian J. Atmos. Environ., 12, pp. 244-254, 2018.

[7] Wang, M. et al.. Air particulate pollution in Ulaanbaatar, Mongolia: Variation in atmospheric conditions from autumn to winter. Sola, 13, pp. 90-95, 2017. 
[8] Urangoo, G. et al., Outdoor Air Pollution and Health in Ulaanbaatar City, Ulaanbaatar, 2019.

[9] Resolution of the Government of Mongolia, On the Prohibition of the Consumption of Raw Coal, 2018.

[10] Lim, M. et al., Characteristics of indoor $\mathrm{PM}_{2.5}$ concentration in gers using coal stoves in Ulaanbaatar, Mongolia. Int. J. Environ. Res. Public Health, 15, 2018. DOI: $10.3390 /$ ijerph15112524.

[11] Ahn, J.Y. et al., Determinants of indoor $\mathrm{PM}_{2.5}$ concentrations in ger, a traditional residence, in Mongolia. Korean J. Public Heal., 55, pp. 22-30, 2019.

[12] Mongolian Statistical Information Service, Population.

[13] Saraga, D. et al., Chemical characterization of indoor and outdoor particulate matter $\left(\mathrm{PM}_{2.5}, \mathrm{PM}_{10}\right)$ in Doha, Qatar. Aerosol Air Qual. Res., 17:, pp. 1156-1168, 2017.

[14] Komarnicki, K., Lead and cadmium in indoor air and the urban environment. 136, 2005. DOI: 10.1016/j.envpol.2004.12.006.

[15] Lai, A.M. et al., Impacts of stove/fuel use and outdoor air pollution on chemical composition of household particulate matter. Indoor Air, 30, pp. 294-305, 2020.

[16] Hill, L.D. et al., Health assessment of future $\mathrm{PM}_{2.5}$ exposures from indoor, outdoor, and secondhand tobacco smoke concentrations under alternative policy pathways in Ulaanbaatar, Mongolia. PLoS One, 12, pp. 1-26, 2017.

[17] Gunchin, G. et al., Three-year long source apportionment study of airborne particles in ulaanbaatar using x-ray fluorescence and positive matrix factorization. Aerosol Air Qual. Res., 19, pp. 1056-1067, 2019.

[18] Davy, P.K. et al., Air particulate matter pollution in Ulaanbaatar, Mongolia: Determination of composition, source contributions and source locations. Atmos. Pollut. Res., 2, pp. 126-137, 2011.

[19] Goddard, S.L. et al., Determination of antimony and barium in UK air quality samples as indicators of non-exhaust traffic emissions. Environ. Monit. Assess., 191, p. 641, 2019.

[20] Amgalan, N., Narantsetseg, T. \& Shagjjamba, D., Valuations of elemental concentrations of particle matter in Ulaanbaatar, Mongolia. Open J. Air Pollut., 5, pp. 160-169, 2016.

[21] Yu, J. et al., Potassium: A tracer for biomass burning in Beijing? Aerosol Air Qual. Res., 18, pp. 2447-2459, 2018. 